\title{
ESTRATÉGIAS POLÍTICAS
}

Empresas e governo são dois agentes fundamentais na dinâmica de qualquer sociedade. A relação empresa-governo também era considerada um dos elementos centrais na economia. A ameaça do comunismo e a saturação do modelo intervencionista do Estado engendraram uma reação ideológica em favor da relação entre empresas em um mercado livre que tomou força no final da década de 1980. Como consequência, o governo foi retirado da equação para explicar a estratégia e vantagem competitiva das empresas. No Brasil, onde o Estado controla recursos importantes para as empresas, a relação entre estas e governo deve ser fortemente considerada nas agendas de pesquisa e na prática da estratégia no Brasil. Pesquisando essa temática desde 2002, o professor Rodrigo Bandeira-de-Mello (FGV-EAESP) apresenta cinco sugestões de leitura sobre a relação empresa-governo e suas implicações na pesquisa em estratégia.

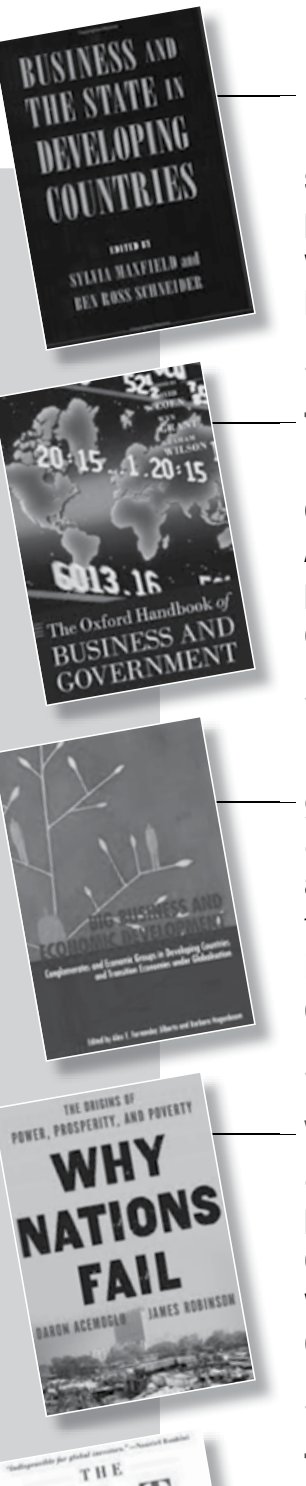

BUSINESS AND THE STATE IN DEVELOPING COUNTRIES. Sylvia Maxfield e Benn Ross Schneider (Orgs.). Ithaca: Cornell University Press, 1997. 360 p. Na primeira parte do livro, as lentes teóricas sobre a relação empresa-governo nos países em desenvolvimento são apresentadas. Na segunda e na terceira partes, os organizadores discutem essa relação em Estados fortes e fracos. São apresentados exemplos de vários países, como Brasil, Coreia, Taiwan e Chile. De origem na ciência política, a obra tem uma tendência Estado-cêntrica, mas não enviesa ideologicamente a temática e serve aos propósitos da estratégia empresarial.

THE OXFORD HANDBOOK OF BUSINESS AND GOVERNMENT. David Coen, Wyn Grante Grahan Wilson. New York: Oxford University Press, 2012. 787 p. Seguindo a linha dos handbooks da Oxford, a obra traz uma série de capítulos que abrangem gestão, economia, história econômica, direito e ciência política. Apesar de também tender para uma visão centrada no Estado, o compêndio oferece uma visão interessante para um leitor da área de estratégia, que pode se beneficiar ao considerar as variedades de capitalismo que estruturam e são estruturadas por essa relação.

BIG BUSINESS AND ECONOMIC DEVELOPMENT: Conglomerates and economic groups in developing countries and transition economies under globalisation. Alex Jilberto e Barbara Hogenboom. New York: Routledge, 2007. 428 p. Apesar de não ser uma obra específica sobre a relação empresa-governo, o livro aborda os grupos empresariais, ou business groups, a forma organizacional típica de países em desenvolvimento. Os grupos empresariais são um instrumento importante para o governo implementar políticas industriais e de desenvolvimento. Entre os tópicos abordados, o livro ressalta a questão da legitimidade dos grupos e o papel do governo na gênese e desenvolvimento dessas formas organizacionais.

WHY NATIONS FAIL: The origins of power, prosperity, and poverty. Daron Acemoglu e James Robinson. New York: Crown Business, 2012. 529 p.0 livro traz uma abordagem institucional econômica para explicar as diferenças observadas na riqueza das nações. Um dos pontos centrais é a lógica dos incentivos que os governantes tiveram para desenvolver determinadas estruturas que inibiram ou facilitaram o desenvolvimento. 0 governo, como um dos formuladores das instituições formais, define regras do jogo e, como consequência, a disponibilidade de recursos para o crescimento e vantagem competitiva das empresas em nível global.

THE FAT TAIL: The power of political knowledge in an uncertain world. lan Bremere

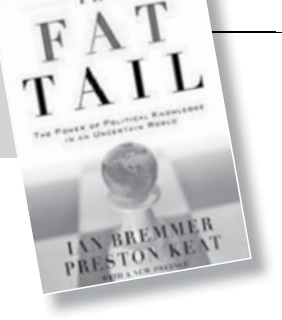
Preston Keat. New York: Oxford University Press, 2010. 272 p. Em linguagem simples, o livro traz inúmeros exemplos de como as empresas podem canalizar suas habilidades políticas para mitigar incertezas e vencer. A ideia da cauda longa refere-se aos eventos pouco prováveis, mas que têm grande impacto na sobrevivência da empresa e estão relacionados ao risco político. Destaque para a definição de "campeões nacionais": empresas usadas pelos governos, principalmente em países emergentes, para ajudar na criação de empregos e ampliar sua influência internacional. 